\title{
Social Media Tools as a Learning Resource
}

\author{
Youmei Liu \\ University of Houston
}

\begin{abstract}
Socialmedia tools have become ubiquitous. You can see our students use them all the time. Among them most popular tools are Facebook, Wiki, YouTube, bulletin board, LinkedIn, blogging, and twittering. The advancement of modern technologies tries its best to accommodate the needs from people, especially the younger generation. As educators, how can we take advantage of this momentum? This paper will share a research study that was conducted in fall of 2009 at the central campus of the University of Houston. The study investigated student's use of different social media tools, their perceptions and attitudes towards these tools, and their preference of social networking groups. The results show that the three top-used social media tools are Facebook, Wikipedia and YouTube; the top four reasons for using social media tools are for social engagement, direction communication, speed of feedback, and relationship building. Regarding social networking group, they preferred a group of civically engaged and no membership required as well as a group based on contemporary topic that may not last long. Based on their input, the author suggested some educational implications of some of these tools as a valuable resource for teaching and learning.
\end{abstract}

Keywords: Social media, social media tools, Web 2.0, social networking, online learning

\section{Introduction}

Web technology has been advanced from static information distribution to massive interaction among users. This development has been labeled as a development from Web 1.0 to Web 2.0. Web 2.0 technologies are emerging every day in spite the fact that there are already more than enough applications for people to use. Web 2.0 technologies not only allow users to be involved in the activities, but more importantly users are the main contributors in this vastly networked Web community, "The barriers to production and distribution have been loosened: an invitation for widespread participation is in place" (Crook, Fisher, Graber, Harrison, Logan, Luckin, Oliver, \& Sharples, p. 3). Web 2.0 technologies are not equally welcomed by Internet users. The interesting phenomenon is the dichotomy between aficionado and antagonist. The younger generation embraces Web 2.0 technologies with great enthusiasm, while the older generation does not even care much about it at all. When this happens in education, it sets a division between students who are fanatic about Web 2.0 applications and gadgets, and instructors who are overwhelmed and struggling by the daily technology changes. Horizon 2009 report raised several challenges in future five years. One of them is the growing 
gap in technology use between students and faculty even though technology use in academia is becoming more and more popular. How can schools keep up with technology investment, and how can faculty members stay abreast of the fast technology change? These are the crucial questions that await intelligent and responsible answers.

There are legitimate concerns for administration. Technology use is not just one time investment. It involves continuing efforts in infrastructure building and expansion. We could still remember there was only one technical person in the department to help faculty fix computer problems. Nowadays, there are IT divisions, departments, offices, and teams at different levels. Responsibilities have been divided into technical support and academic training and consultation. This expansion has exhausted a huge amount of financial and human resources. On top of that, there might be a big online program investment. For example, quite a few high institutions are using professional Course Management Systems (CMS) such as Blackboard, Desire2Learn, eCollege, etc. These systems need maintenance and constant upgrades. Once a school has implemented the CMS, it is very difficult to stop using the system.

On the side of academia, we still have faculty who firmly believe that traditional classroom teaching is the most effective way to reach out to our students. But with the fast increase in educational demand, limited classroom space has become a learning barrier. There are simply not enough classrooms to accommodate the growing needs from students. Besides, the student body has been undergoing a dramatic change. Non-traditional student population is increasing on a daily basis. According to our recent statics at the University of Houston, there are only about $10 \%$ of students who are living on campus; about $90 \%$ of students are commuters. Their average driving distance is about 18 miles one way. Nearly $90 \%$ of them either have part-time or full-time jobs. Technology integration has become a must to meet their learning needs.

Our students have been labeled as Digital Natives by Marc Presky (2001). He defined today's students as "they spent their entire lives surrounded by and using computers, videogames, digital music players, video cams, cell phones, and all the other toys and tools of the digital age" (p. 1). When Web 2.0 social media technologies emerged in the market, students quickly bond themselves to those tools such as YouTube, iTunes, Facebook, blogging and twittering, to mention a few. These applications were not developed for learning purposes. Most people use them for recreational purposes such as "gaming, communication, and shaping online spaces for expression of personal identity" (Crook, et al. 2008, p. 4). Yet, social media tools are wonderful communication tools. The functions of some social media tools are similar to those in the fancy CMS. If we use those tools wisely and integrate them in teaching process, we can leverage student technology skills for learning purposes, and even cut back institutional financial investment and lessen the burden from faculty for student technical support. The fast emerging social media tools could shift the local technology investment to a universal investment. With the aim of taking a full advantage of this public resource, knowing what our students are using and how they are using the social media tools is absolutely necessary for schools and faculty to integrate those tools in teaching and learning activities.

At most schools, on-campus technology integration is a top-down process. Faculty and students use the technology that was selected by IT people. Rarely the IT people would conduct an investigation among faculty and students 
to find out what kind of technology they use and want to use. Chances are what students and faculty are using is not what the schools have implemented. The technologies used by our students are mostly commercial social networking and entertainment applications, so what the students know is not necessarily what schools have implemented.

\section{The Study}

In order to find out the knowledge and trend of using social media tools and what kind of resource existing among our students, the office of Educational Technology and University Outreach (ETUO) conducted a research study in fall semester of 2009 at the University of Houston (hence UH), central campus. Random sampling was used to collect data through an online survey. Four classes participated in the study with a total number of 221 students from the Jack J. Valenti School of Communication and Bauer College of Business. Those classes were selected because the instructors in those classes were willing to support the study.

\subsection{Participants}

Students from the School of Communication were mostly juniors and seniors. And, the students from Bauer College of Business were seniors and graduates. There was a good mixture of students from undergraduate and graduate levels. See Figure 1 for detailed academic division.

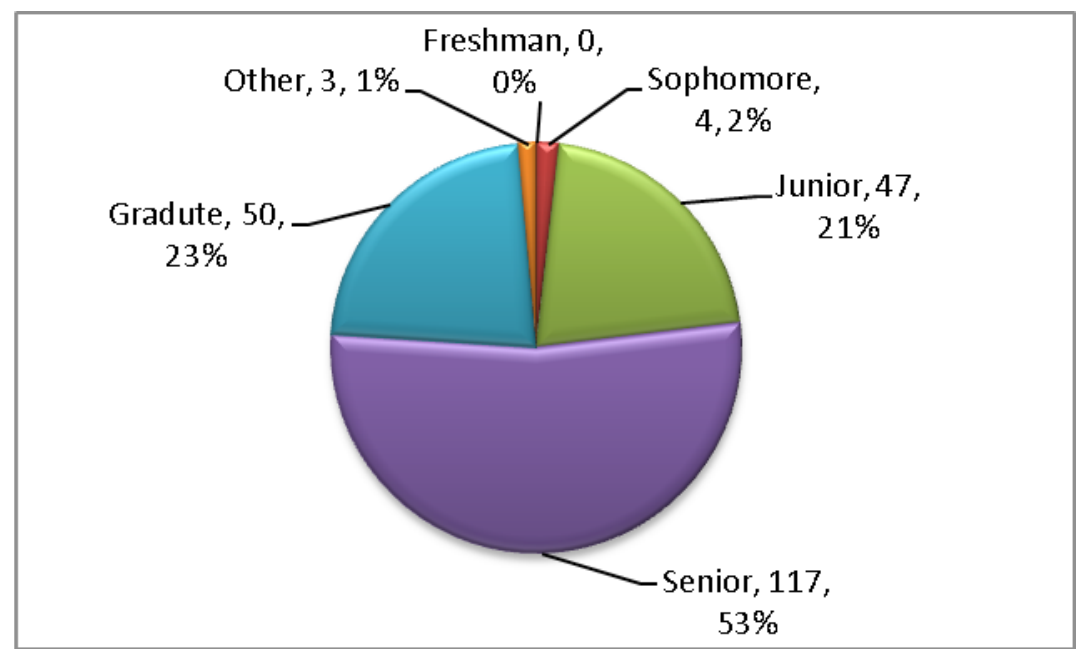

Figure 1. Student Academic Status

The combined senior student group takes up the largest percentage, which is $53 \%$, and it was followed by graduate students at $23 \%$. The third place is junior students with $21 \%$. There were no freshmen students reported.

\subsection{Instrument}

The online survey questionnaire consists of 41 items, which are divided into three sections. Section 1 consists of 7 demographic questions about participant's gender, age, academic status, 
credit hours, employment status, ethnicity and marital status. This section intends to collect the data to find out if they have any impact on the adoption of social media tools and different perceptions and attitudes towards social media tools use. Section 2 has 12 questions, which collect data on student level of knowledge about social media tools, which will provide information on the potential resource that can be used for learning purposes. Lastly, section 3 is composed of 22 questions related to student perceptions and attitudes towards social media adoption, rejection, and social networking preferences.

\subsection{Data Analysis}

The collected data were analyzed by using SPSS. There were two types of analysis. Descriptive analysis to find out the distribution of social media concept and knowledge, social media tools adoption, participant perceptions and attitudes towards social networking and social trust issues were conducted. ANOVA analysis was used to compare the different groups based on the demographic information to find out if those demographic differences will have any influence on social media knowledge acquisition, any impact on the social media tools adoption, and preference on social networking selection. In this paper, only descriptive data will be reported.

\section{Data Report}

In this paper, only selected data are reported and covers five aspects. The demographic information provides a big picture of the participants. The concept of social media presents the data on student knowledge of social media concept and media tools. Social media adoption ranks the popularity level of the social media tools utilized by students. Social media and trust reflect student trust tendency and attitudes towards social media tools in public interaction. Social networking group preferences list student favored grouping format and topics.

\subsection{Demographic Information}

The survey collected student demographic information in regard to their gender, age, ethnicity, and marriage status with the intention to find out if these variables would affect student perceptions and attitudes towards social media and their use of social media tools. With this population, there was almost an equal division of gender, $51 \%$ of females and $49 \%$ of males. $59 \%$ of students were in the age group of 18 to $24,36 \%$ belonged to age 25-34 group, and only $5 \%$ of students who were between 35 44. The largest ethnicity group was white or Caucasian students, who took over $35 \%$, and it was followed by Asian students with $28 \%$. Hispanic students were $21 \%$ and Black or African American group was 14\%. Two other ethnicities were also reported with $1 \%$ each, which were American Indian and Native Hawaiian. With regard to marital status, almost $60 \%$ of students were single, $21 \%$ of students were dating, $16 \%$ of students were married, and $4 \%$ reported divorced. Based on the ANOVA analysis, $p$-values indicate that there is no significant difference between genders, among age groups, marital groups and ethnicity groups with regard to the knowledge of social media concept (the p-value threshold was set to 0.05$)$.

\subsection{The Concept of Social Media}

The study investigated student knowledge about the concept of social media (see Figure 2). $94 \%$ of students were familiar with social media concept varying at different levels; only $6 \%$ of students were not familiar with social media concept. It is noticeable that almost one third of the students were very familiar with the concept. 


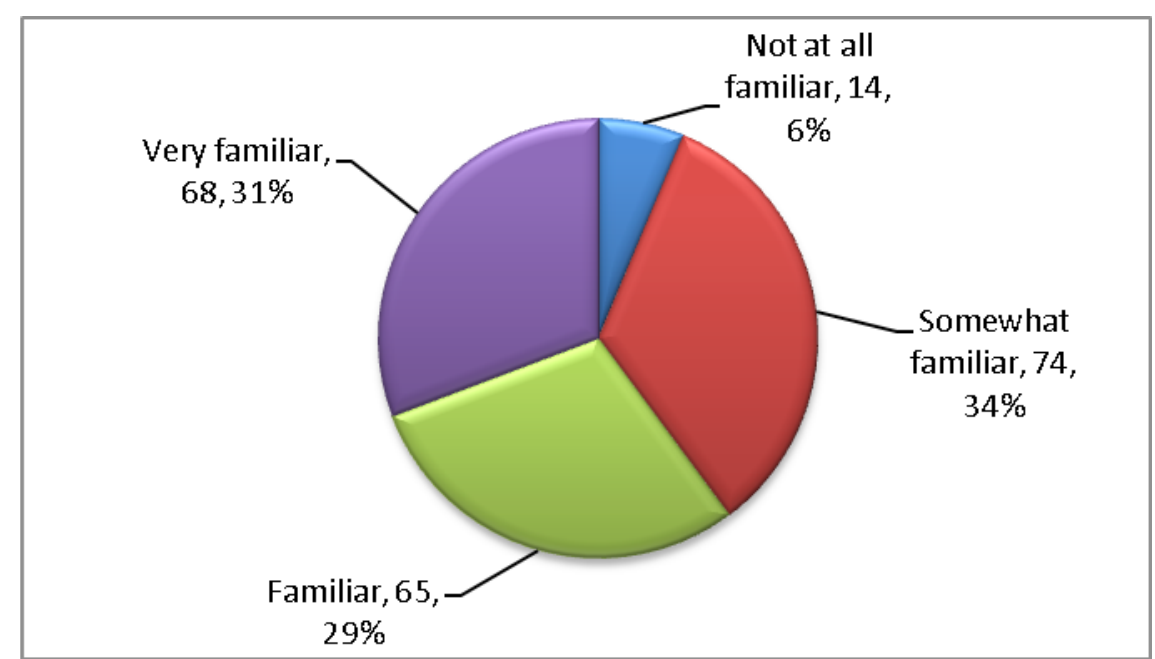

Figure 2. Student's Familiarity with Social Media Concept

Table 1. Student Knowledge Level of Top 7 Social Media Tools

\begin{tabular}{lccccccc}
\hline & Facebook & Forum & Blogging & YouTube & Podcasting & Twitter & Wiki \\
\hline $\begin{array}{l}\text { Very } \\
\text { Knowledgeable }\end{array}$ & $31 \%$ & $24 \%$ & $14 \%$ & $41 \%$ & $10 \%$ & $8 \%$ & $30 \%$ \\
Knowledgeable & $39 \%$ & $33 \%$ & $37 \%$ & $41 \%$ & $28 \%$ & $22 \%$ & $47 \%$ \\
$\begin{array}{l}\text { Somewhat } \\
\text { Knowledgeable }\end{array}$ & $29 \%$ & $39 \%$ & $41 \%$ & $16 \%$ & $42 \%$ & $45 \%$ & $21 \%$ \\
$\begin{array}{l}\text { Not at all } \\
\text { Knowledgeable }\end{array}$ & $1 \%$ & $4 \%$ & $8 \%$ & $2 \%$ & $20 \%$ & $25 \%$ & $2 \%$ \\
\hline
\end{tabular}

There were sixteen social media tools presented to students in the survey. They were Facebook, Wiki, YouTube, bulletin board, LinkedIn, Blogging, Twitter, Podcasting, Virtual Worlds, RSS, StumbleUpon, Netlog, Delicious, Digg, Plurk, and Jaiku. Table 1 shows the top seven tools that students were knowledgeable of at different levels.

Before this survey was conducted, there was a high estimation that most students knew about twittering, but the results show that there were $25 \%$ of students who did not have knowledge about it at all, and $45 \%$ of students had somewhat knowledge about it. Only 8\% of students were very knowledgeable about it. As predicted, Wiki tool is very popular among students, as high as $77 \%$ of students either very knowledgeable or knowledgeable about this tool. Virtual Worlds have been pretty hot in recent years; the most well-known application to the public is Second Life, and the results show that $42 \%$ of students did not know Second Life at all. Another tool was RSS, which became 
commercially popular with the increased use of podcasting. RSS push technology is very useful in automating information feeding for end-users. But again, the results show almost $40 \%$ of students had no knowledge of it at all. Always a recommended practice is that before any social media tools are implemented in the teaching process, it is necessary to find out what tools students are using. Their readiness needs to be warranted before the deployment.

\subsection{Social Media Adoption}

People use social media tools for various reasons. The survey was also set to find out student perceptions of social media adoption.
The understanding can help instructors design activities meaningfully and use the tools effectively. Figure 3 indicates that social engagement is the top reason for social media adoption. It is followed by direct communications, quick feedback/results, relationship building, and the ability to reach new friends. All this reflects social networking establishment and interactive communication amongnetworking members. Other reasons have also been reported such as low communication cost, gain insides, ability to influence others, public research/polling, expert positioning, and credibility of the public.

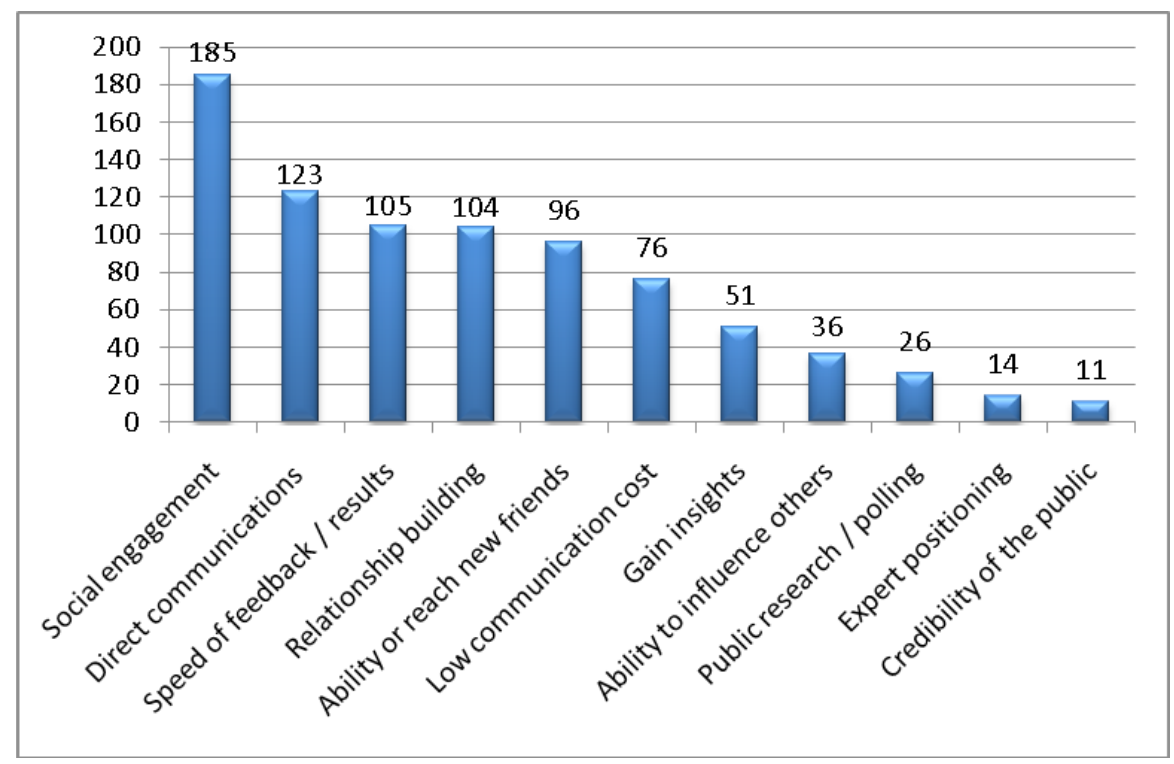

Figure 3. Main Reasons Driving Social Media Adoption

In students' free input, being able to connect with old friends is another strong reason for social media tool adoption. Commercial advertisement has increased use of social media tools to reach more potential customers. Few students mentioned about the educational use for research projects, learning resources, and team work. 


\subsection{Social Media and Trust}

Because social media tools are mostly free applications for public use, users' background is very diverse. Some people refuse to use any social media tools due to untrusted sources. Nobody could really be sure what is truly happening on the other end of the wire. Online identity theft has led to numerous cases of financial even physical damages. If we want to integrate social media tools as a learning resource, we need to find out student attitudes towards public trust. The results indicate that about half of the participants did not believe that the public was trustworthy and $94 \%$ of students thought that social media policy and guidelines were important at different levels (14\% - very important, $45 \%$ - important, and $37 \%$ somewhat important). The top two reasons they perceived as barriers to social media adoption are fear of untrusted sources and uncontrollable nature of social media or lack of privacy control. Most of them (77\%) believed that people are interested in their own welfare generally. But, when they were using social media tools to communicate and interact with their close friends and family members, their trust is no longer an issue (see Figure 4). 92\% of students either strongly agreed or agreed that when they were communicating with their close friends or family members, they trusted them.

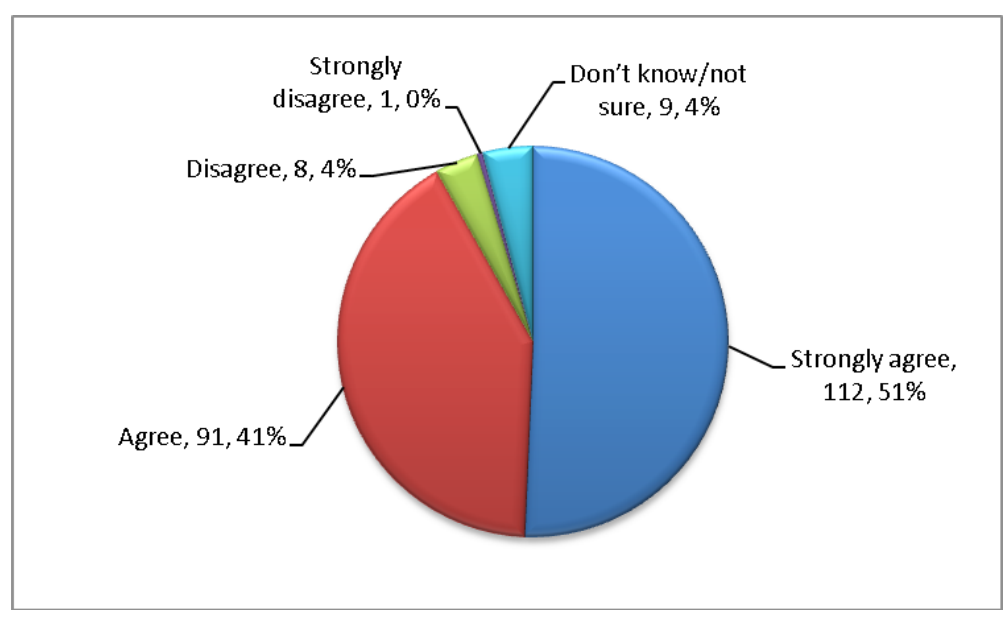

Figure 4. Social Media Use to Trust Close Friends and Family Members than Others

There is an interesting phenomenon in the results. Students had trust issues when they were using social media tools $(50 \%)$, but there were almost $70 \%$ of students considered that most people in social community were willing to help and $70 \%$ of students would pay attention to the opinions of others when they were communicating via social media tools.
Almost $80 \%$ of students felt that they were accepted as social community members. 50\% of students reported that they provided helpful information to others and about $30 \%$ of students tried to influence others with their ideas while using social media tools. In both cases, when they communicate with their close friends and family members, they provided more helpful 
information $(70 \%)$ and tried to influence more as well $(37 \%)$. From here, we can see that students communicating at different levels with different target audiences. With trusted audiences, they provided more information and with more influence. In their responses to the reasons of social media tools adoption, two of the top reasons stated by students are direct communication and speed of feedback and results, which contributed to the use of social media tools to find answers and solutions to the problem from students. The results show that $57 \%$ of students would use social media tools for problem-solving.

\subsection{Social Networking Group Preferences}

Social media tools have been claimed to be effective social networking tools. People network themselves with different intentions and for different purposes. There are various social networking communities with vast interests such as politics, religion, profession, recreation, etc., and in different format such as government, institution, non-profitorganization, membership, club, etc. Figure 5 shows students' preference in joining social groups through social media tools. Each student could join up to three personally preferred groups. Eight groups were provided.
A. A group with strong bonding and intensive beliefs meets regularly
B. A group based on contemporary topic which may not last long
C. A group organized by governmental institutions
D. A group of non-authority and decentralized
E. A group of civically engaged and no membership required
F. A group with protected membership
G. A group with membership as social collateral or individual wants
H. A group with membership as bounded solidarity

The above eight groups can be loosely combined into four types, (1) contemporary and civically and no-membership group $(\mathrm{B}+\mathrm{E}$, 226), (2) membership group ( $\mathrm{F}+\mathrm{G}, 140)$, (3) strong and intense bonding group $(\mathrm{A}+\mathrm{H}, 85)$, and (4) governmental institution group (C. 31). The first group outnumbered the rest of the three.

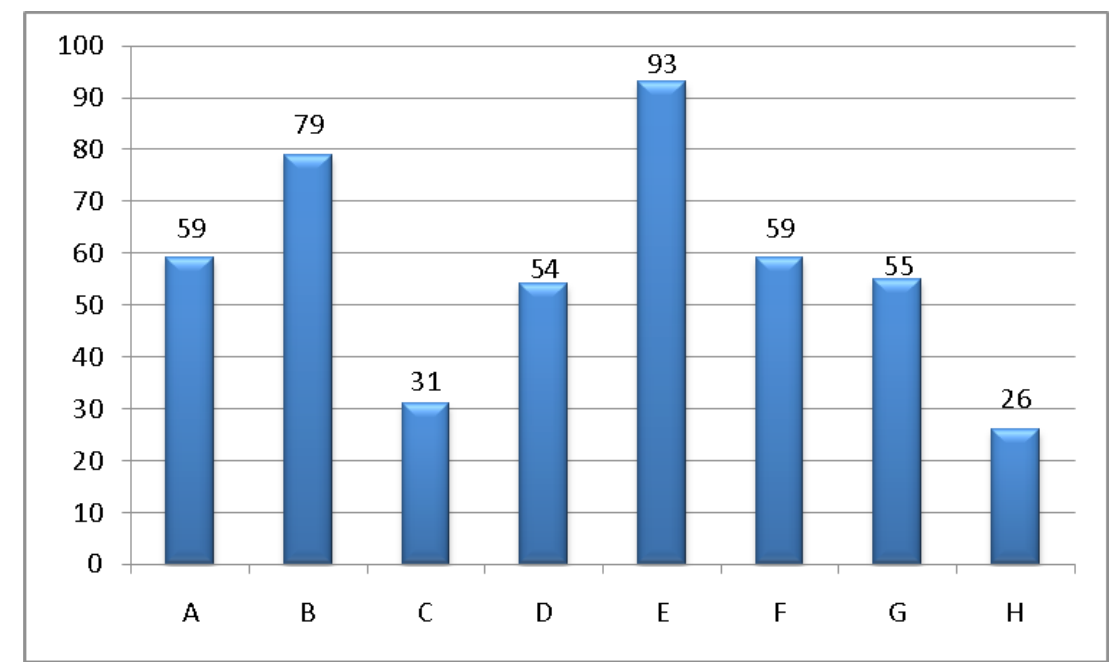

Figure 5. Students' Preference of Joining Social Groups through Social Media Tools 
A group of civically engaged and no membership required was the most preferred group by the students (42\%), and followed by a group based on contemporary topic which may not last long (36\%). There were $27 \%$ of students liked to joining a group with strong bonds and intensive beliefs and equal amount of students preferred membership to a protected group. The further study will find out if age or ethnicity or gender would be an influencing factor for their group selection. From the results here, it is definite that a majority of them prefer contemporary topics and a decentralized group with civilized engagement.

\section{Discussion and Implications}

Social media is gaining its momentum at an unimaginable speed. It indicates that we, as social beings, need constant connection with each other and with the outside world. The world is more open than ever before with tremendous opportunities for exchanging of ideas, experiences, and intelligence due to the rapid advancement of technologies. Social media found its way quickly into the commercial world, at the same time educators are seeking possibilities of leveraging social media tools in educational arena. Social media tools provide learners with new opportunities to become independent in their study and research. They encourage a wider range of expressive capacity (Crook, et al, 2008). UH research study indicated that student's use of wiki and YouTube is increasing and have become very popular.

There are mainly two ways to use social media tools for educational purpose. One way is to integrate social media tools into the current educational system as a teaching and learning resource to assist the process of curriculum delivery. Now, we can see a gradual merging of those tools with CMS. This is a wise move with the least interruption of exiting curriculum delivery system. Another way is to use social media as a parallel learning channel to compliment current curriculum delivery, and to extend the learning environment to the real world and to enrich students learning experiences with real life practice. The second way will be more challenging and difficult to implement and manage for current education status quo. Here, we will focus on the first way of social media integration in education. Based on the results of the study, the top-used social media tools by students at UH are shown in Figure 6 on the next page.

Among these tools, Facebook, Wiki, and YouTube are the top used tools. This section will discuss these top three tools, and how they have been used in the educational practice. Each tool is unique in its own way, and each of them has both strengths and weaknesses. When we plan to integrate these tools, we need to be cautious to make sure we leverage the strength and avoid unnecessary quandaries that might hinder student learning. If the tool cannot help the instructor improve teaching efficiency, why bother? Another precaution for technology integration is that not every tool is equally efficient for every subject area. Technology is like a tool in our daily life; each tool has its own features and only good for its purpose as it was designed for. If used improperly, the tool can cause more nuisance than providing help. So, the advice here is to use the tool when appropriate for the content, subject area, and learning activities. Understanding students and their skill sets before implementation can help increase cost-effectiveness. 


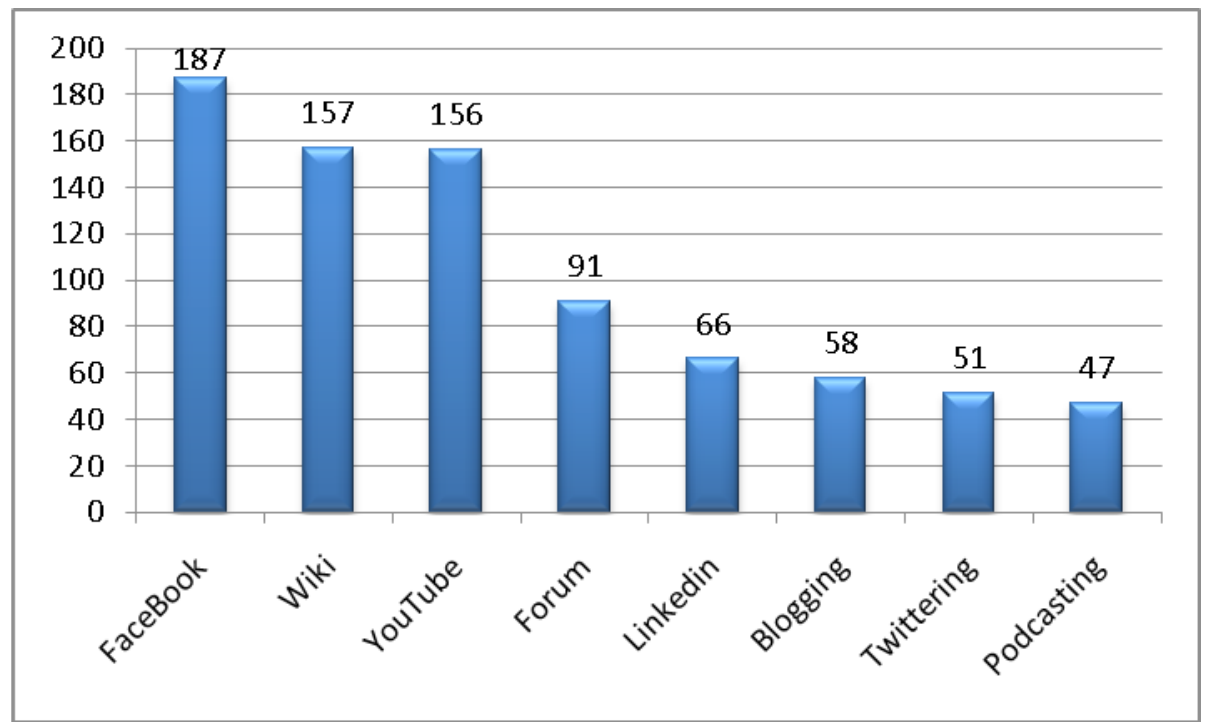

Figure 6. Top-Used Social Media Tools by Students at UH

\subsection{Facebook}

According to Facebook Web site statistics, there are more than 400 million active users from over 180 countries right now, more than 60 million status updates posted each day, more than 3.5 million events created each month, and more than 3 billion photos uploaded each month (Facebook, April 2010). Facebook has the following features: user's profile, status, friends, news feed, wall, discussion boards, photo tagging, and applications. Based on these features, Facebook could be a wonderful tool for building a sustainable and life-long learning social network and building an extended community learning environment.

Most students already have Facebook accounts with their personal profiles setup. On their Facebook wall, they have all sorts of information, including photos about themselves and their networking group. The established personal profile can be used as a tool for icebreaking, so that students and instructor can get to know each other in much more depth than a simple self-introduction in class. It can serve as a community learning starter. Students can build a deep-level bonding relationship based on their common interests, hobbies, similar life styles, etc. The biggest benefit of using Facebook as a community learning tool as opposed to using communication tools in CMS is the continuity after the academic semester/school is over. Students will be able to keep in touch with classmates and even become connected with friend's friends. They are building their learning community together with social networking, and expanding this relationship with the progression of school years and life span. Besides, the access of Facebook is much more dynamic than CMS via portable networks.

Another difference of using Facebook vs. CMS is that anything uploaded to Facebook will be on the Facebook's server, and if you do not use privacy setting, everything will be public. For certain class activities, to limit the access to the class members is absolutely necessary. So, setting up privacy is necessary 
for some classes. But on the flip side of this, instructor can take advantage of this open learning environment to fully engage students in an authentic learning. For example, for certain social issues or projects, students can extend the discussion forum or activities to the public and to find out not only what peers think about, but also what public's opinions towards the same issue. Instructors can guide students in data synthesis and analysis to promote students' deep-level learning and to nurture their critical thinking skills. Traditional learning has long been separating classroom knowledge with the reality of the society. What students learn is not applicable to what the society needs. Involving community in the learning process can help students identify the knowledge that is useful and applicable, and help them have a better understanding of the environment and circumstances that knowledge will be used to increase the value of education.

There are some benefits of using Facebook for educational purposes, but after all, Facebook is not a professional course delivery system. It should not be used as a stand-alone educational tool, yet we can capitalize on Facebook's ubiquity and collaboration capabilities (Guess, 2008). Education is not just about using another fashionable technology tool; it is about quality communication achieved through the tool.

\subsection{Wiki}

The growing use of Wiki is mostly for learning resources and collaborative projects. It is the second highly-used tool among students in the study. As learning resources, everyone knows where to go to: http://www.wikipedia. org. This resource Website has exceeded authoritative encyclopedia Britannica, "The bottom-up, dynamic, nonprofit, Web-based encyclopedia continues to mushroom in popularity (about 2.5 billion page views per month) and size (more than 873,000 articles and
43,000 contributors associated with the Englishlanguage version, and more than 89,000 total volunteers working on over 2,550,000 articles in more than 200 languages)" (Berinstein, I 2). The key issue has been standing out for using Wikipedia as information resource is the reliability. Most of the authors for Wiki are volunteers and at younger ages (between 25-35) without a high academic background, let alone authoritative figures in that research area. On the other hand, Britannica's authors are chosen based on their professional expertise and some are Nobel Prize winners, university professors, and experts in their research area. But, why is wiki attracting the public so fast? "Wikipedia exemplifies a fascinating new paradigm. It is open to everyone, not only to read, but also to create and maintain, and governed primarily by community consensus" (Berinstein, 2009), or it is owned by the people who work on it. From a certain perspective, Wikipedia is under more supervision than Britannica because the content reliability can be challenged by the public. The accuracy of Wikipedia article is improving. The end of the argument is not really which one is better. They both are information resources. The important takeaway for our students is that they need to learn how to comprehensively look at the information available to them, and use appropriate analytical skills to make the best use of the resources instead of taking whatever is presented to them without sound judgments. Instructors should incorporate skill trainings in how to digest different online resources.

Another wiki use in education is the collaborative wiki application. Students can work together in teams collaboratively on projects. There are a lot of useful features with wiki applications, and students can develop project in stages and peer review their products. Wiki application has also been used for collaboration with local communities to involve experienced professionals to enhance learning experiences. In this extended learning 
community, students can learn directly from the field people. UH has been conducted a case study in the past two semesters, where business students, most of them were either seniors or graduates, designed group projects with experts in fields. They were using wiki applications to interact and communicate with those experts throughout their entire projects. Students were able to learn a lot of knowledge that was not covered in the textbook and they benefited tremendously for their future careers.

\subsection{YouTube}

According to Clean Cut Media (http:// www.cleancutmedia.com/video/youtubestatistics-the-ultimate-time-suck), YouTube is the 4th largest Web site in the world, and there are 100 million visitors each month. YouTube has dedicated a special channel for education called TeacherTube for teachers to upload instructional materials and share with other educators. It provides great resources for both teachers and students. Furthermore, about a year ago, YouTube released another education related site, YouTube EDU, that aggregated thousands of free lectures from close to 400 universities across the country, which was influenced by MIT open source initiative in early 90's. This resource allows educators and eager learners to access valuable learning content at no cost. The spreading of knowledge is phenomenal, and it is a better way to collect and highlight all the great educational content being uploaded to YouTube by colleges and universities (Arrington, 2009). There are evidences in education that YouTube has been used for the following purposes:

- Class videos have been provided for student flexible learning

- Use videos as visual aid to help students better understand the learning content

- Use videos to address student different learning styles.
- Use videos as research resources

- Student produced videos for projects

The creative use of technology has no limits by creative minds. YouTube has many features that can help educators with content delivery. For example, it can enhance presentation, translate video caption to a different language to increase the accessibility to other language learners, and allows one to embed videos needed at any location necessary to enhance teaching effectiveness. YouTube has quickly become a learning tool due to its ease of use. Wherever there is an Internet connection, YouTube videos are available to viewers. It does not require a browser plug-in and a third-party application to manage the content as in iTune's podcasts. A research study conducted at the UH in spring 2009 involved a large chemistry class that was using both iTunes Podcasts and YouTube videos. The results indicated that over $70 \%$ of students were using YouTube videos and less than $30 \%$ of students were using podcasts. The reason is simple; YouTube is much easier to access. When YouTube videos are used as an academic learning resource, one precaution that students need to be aware of is the credibility of the content if public material is used for educational purposes. Both instructors and students need to investigate the credibility and reliability of the source to make sure the data are accurate and valid. Students can improve their analytical skills through this process.

\section{Conclusion}

With the fast advancement of technology, there will be more cutting-edge technologies appearing in that market on a daily basis. As educators, should we ignore them or chase after them? It is always a huge challenge to keep up with new technology trend. It is much more important to understand the nature of technology in the process of education than technology integration itself. No matter how 
fascinating a new technology can become, it is still a tool. Technology should not and will never replace education, but assist educational practice, improve teaching efficiency, and enhance student learning experiences.

The emerging social media tools that we investigated and discussed in the paper are existing resources among students. We should take advantage of this resource to make learning more accessible. Students feel comfortable to use the tools that they already know. Social media tools are an open resource, which also means they are open to uncensored public. It is educators' responsibility to make sure this learning environment is protected for the best interest of student learning. It is also the responsibility of educators to train students and equip them with analytical and deep thinking skills during the process of using social media resources. Intelligent adoption of social media tools can engage students in interactive learning, which is the key to a successful education.

Using social media tools in teaching sometimes can be very challenging to instructors. Students can be a very good consulting source because they are the experts and they have a better understanding of the tools. The future technology integration in education should focus on what students use instead of what the school wants them to use to guarantee maximum efficiency. When students become the stakeholders of their own learning, education will be truly revolutionalized through the effective collaboration between educators and students.

\section{References}

Arrington, M. (2009). YouTube EDU launch, So Go to Learning Something. Retrieved on April 23, 2010 from http://techcrunch.com/2009/03/26/you tube-edu-launches/ \#ixzz0m5GoZUtZ

Berinstein, P. (2009). Wikipedia and Britannica. Retrieved on April 24, 2010 from http:// www.infotoday.com/searcher/mar06/ Berinstein.shtml

Crook, C., Fisher, T., Harrison, C., Logan, K., Luckin, R., Oliver, M.,\& Sharples, M. (2008). Web 2.0 technologies for learning: the current landscape - opportunities, challenges and tensions. Retrieved on May 7, 2010 from http://partners.becta.org.uk/ upload-dir/downloads/page_documents/ research/web2_technologies_learning.pdf

Facebook. (April 2010). Statistics. Retrieved on April 21, 2010 from http://www.facebook. com/press/info.php?statistics

The Horizon 2009 Report. The New Media Consortium, EDUCAUSE Learning Initiative. Retrieved on April 15, 2010 from http://www.nmc.org/pdf/2009-HorizonReport.pdf

Prensky, M. (2001). Digital Natives, Digital Immigrants. On the Horizon, Vol. 9 No. 5, October 2001. (p. 1-p.5).

Guess, A. (2008). Facebook, meet Blackboard. Retrieved on April 21, 2010 from http://www.insidehighered.com/news /2008/05/14/sync 


\section{Contact the Author}

Youmei Liu, Ph.D.

University of Houston, USA

E-mail: lyoumei@yahoo.com 